\title{
ANALISA KINERJA KONEKSI JARINGAN KOMPUTER PADA SMK TEKNOLOGI BISTEK PALEMBANG
}

\author{
Muhammad Fajri, M.Kevin Setiawan \\ Mahasiswa Universitas Lancang Kuning \\ e-mail :fajri.rgt118@gmail.com, kevinsetyawanvevo@gmail.com,
}

\begin{abstract}
Abstrak : Jaringan komputer adalah dua komputer dapat dikatakan saling terkoneksi dalam sebuah jaringan jika keduanya mempunyai kemampuan untuk saling berkomunikasi dan bertukar informasi. Untuk memberi sebuah koneksi jaringan komputer keseluruh pengguna dalam area disekitarnya. Dalam tugas akhir ini, peneliti memilih tempat di sekolah SMK Teknologi Bistek Palembang untuk menganalisis kinerja jaringan komputer dan topologi yang digunakan adalah topologi star. Dimana dalam melakukan aktivitas kerja pada saat mengakses jaringan, mengolah data, sharing resources pada jaringan internet koneksi jaringannya kurang stabil karena permintaan akses yang tinggi seperti mengirim email, mendownload, sharing file antar komputer sehingga membuat terganggunya aktivitas menggunakan internet yang membuat para pengguna tidak nyaman dalam penggunaan internet. Dari permasalahan tersebut memunculkan gagasan untuk melakukan penelitian agar dapat mengetahui apa penyebab dari permasalahan yang ada dengan melakukan pengukuran terhadap parameter $Q o S$ yang terdiri dari bandwidtch, delay, throughput, dan packet loss. Dalam pengukuran kinerja koneksi jaringan komputer ini menggunakan metode $Q o S$ (Quality of Service) untuk mengetahui jumlah bandwidtch, throughput, delay dan packet loss berdasarkan standar THIPON.. Selain itu penelitian ini juga menggunakan metode action research, dengan tahapan penelitian melakukan diagnosing, action planning, action taking, evaluating dan learning. Maka dapat diketahui seberapa cepat koneksi jaringan, dimana hasil dari penelitian ini berguna untuk manajemen perangkat jaringan komputer yang ada di SMK Teknologi Bistek Palembang agar dapat mengetahui kelemahan dari setiap node dan jaringan yang ada di SMK Teknologi Bistek Palembang.
\end{abstract}

Kata Kunci : Jaringan Komputer, QOS (Quality Of Service), THIPON, Action Research.(AR)

Abstract: The computer network is two computers can be said to be inter-connected in a network if they both have the ability to communicate and exchange information. To provide a computer network connection to all users in the surrounding area. In this thesis, the researchers chose a place at the Technological Bistek Palembang to analyze the performance of computer networks and topologies used is the star topology. Where in doing work activities at the time of accessing the network, processing data, sharing resources on the Internet network connection is less stable because demand high availability such as sending emails, downloading, sharing files between computers so as to make the disruption of activities using the Internet that makes the user uncomfortable in internet usage. Of these problems led to the idea to do some research in order to find out what the cause of the existing problems with measuring the QoS parameters consisting of bandwidtch, delay, throughput, and packet loss. In the measurement of the performance of this computer's network connection using QoS (Quality of Service) to determine the amount bandwidtch, throughput, delay and packet loss based on standards THIPON .. Besides this research also use action research method, the research stages do diagnosing, action planning, taking action, evaluating and learning. It can be seen how quickly the network connection, where the results of this study are useful for device management of computer networks existing in SMK Technology Bistek Palembang in order to know the weaknesses of each node and network existing in SMK Technology Bistek Palembang.

Keywords: Computer Network, QOS (Quality Of Service), THIPON, Action Research. (AR) 


\section{PENDAHULUAN}

\subsection{Latar Belakang}

Perkembangan teknologi pada saat ini berkembang sangat pesat, kemajuan yang diciptakan oleh teknologi sangat bermanfaat bagi manusia khususnya pada perusahaan, rumah sakit, perguruan tinggi dan lain - lain. Seiring berkembangnya teknologi tersebut, penggunaan komputer - komputer otonom menjadi tidak efisien lagi karena sudah semakin banyak perkerjaan yang membutuhkan kemampuan sharing resources, intergrasi data, dan keamanan data pada komputer tersebut.

SMK Teknologi Bistek Palembang adalah sekolah menengah kejuruan swasta dengan gedung milik sendiri pada tahun 2002, awal mula berdiri SMK Teknologi Bistek menggunakan nama manajemen bistek yang memiliki 2 Program Studi, yaitu Administrasi Perkantoran (AP) dan Teknik Komputer Jaringan (TKJ). SMK Teknologi Bistek ini beralamat di Jln. Animan Achyad (Sukabangun II), No.1446, Kelurahan Sukajaya, Kecamatan Sukarami, Kota Palembang.SMK Teknologi Bistek Palembang pada saat ini sudah menggunakan jaringan komputer, koneksi jaringan komputer menggunakan switch sebagai koneksi jaringannya. Jaringan komputer merupakan sebuah kebutuhan yang semakin banyak digunakan. Secara umum yang disebut jaringan komputer adalah beberapa komputer yang saling berhubungan dan melakukan komunikasi satu dengan yang lain menggunakan perangkat keras jaringan (ethenet card, token ring, bridge, modem dan sebagainya. Komputer yang berada didalam suatu jaringan dapat melakuakn tukar menukar informasi atau data dengan komputer lain yang berada dalam jaringan tersebut (Wahana komputer, 2005:01).

\subsection{Perumusan Masalah}

Berdasarkan latar belakang yang telah diuraikan diatas, maka masalah yang dapat dirumuskan adalah Bagaimana menganalisa kinerja koneksi jaringan komputer pada SMK Teknologi Bistek Palembang ? "'

\subsection{Batasan Masalah}

Adapun batasan masalah pada penelitian ini yaitu “ Menganalisa kinerja koneksi jaringan komputer dengan melakukan pengukuran pada parameter kualitas layanan yang meliputi parameter bandwidth dengan menggunakan Biznet Speed Meter dan delay, throughput, dan packet loss menggunakan Axence NetTools versi 5 pada SMK Teknologi Bistek Palembang ".

\subsection{Tujuan dan Manfaat Penelitian}




\subsubsection{Tujuan Penelitian}

Adapun tujuan yang dicapai dalam penelitian ini adalah untuk menganalisa kinerja koneksi jaringan komputer dan agar mengetahui jumlah bandwidth, delay, throughput, dan paket poss pada SMK Teknologi Bistek Palembang.

\subsubsection{Manfaat Penelitian}

Adapun manfaat dari penelitian ini adalah :

1. Untuk mengetahui kinerja koneksi jaringan komputer.

2. Untuk mengetahui faktor-faktor apa saja yang mempengaruhi kinerja koneksi jaringan komputer pada SMK Teknologi Bistek Palembang.

\subsection{Metodelogi Penelitian}

\subsubsection{Tempat Dan Waktu}

\section{Penelitian}

Penelitian dilakukan pada SMK Teknologi Bistek Palembang yang beralamat di JIn. Animan Achyad (Sukabangun II), No.1446, Kelurahan Sukajaya, Kecamatan Sukarami, Kota Palembang. Penelitian dimulai pada bulan Oktober sampai bulan Februari 2017.

\section{TINJAUAN PUSTAKA}

\subsection{Tinjauan Umum}

\subsubsection{Sejarah SMK Teknologi}

\section{Bistek Palembang}

SMK Teknologi Bistek Palembang merupakan sekolah menengah kejuruan swasta dengan gedung milik sendiri yang berdiri pada tahun 2002, awal mula berdiri SMK Teknologi Bistek Palembang menggunakan nama menejeman bistek yang memiliki 2 Program Studi, yaitu Administrasi Perkantoran (AP) dan Teknik Komputer Jaringan (TKJ). SMK Teknologi Bistek Palembang beralamat di Jln. Animan Achyad (Sukabangun II ), No. 1446, Kelurahan Sukajaya, Kecamatan Sukarami , Kota palembang. Pada tahun 2009 manajemen bistek mengalami perubahan nama sehingga menjadi SMK Teknologi Bistek Palembang.

\subsubsection{Visi \& Misi SMK Teknologi Bistek Palembang}

\subsubsection{Visi}

Membangun manusia handal, propesional, terampil, produktif, berjiwa mandiri, berorientasi pasar kerja teknologi industri melalui pendekatan link and match dan program plus industri.

\subsubsection{Misi}

1. Mengsosialisasikan SMK TI dan B.Indosains Sebagai Sekolah Plus 
bahasa. Inggris dan produksi kepada dunia usaha/ industri dan masyarakat umum.

2. Menjalin kerjasama dengan dunia usaha / industri yang saling menguntungkan disegala bidang.

3. Meningkatkan mutu Sumber Daya Manusia (SDM) siswa, guru, instruktur, dan pegawai sesuai dengan bidangnya masing-masing.

4. SMK Teknologi Bistek

Palembang menjadi sekolah plus, favorit dan unggul.

\subsection{Landasan Teori}

\subsubsection{Analisa}

Analisa adalah sebuah teknik pemecahan masalah yang menguraikan sebuah sistem menjadi bagian - bagian komponen dengan tujuan mempelajari seberapa bagus bagian - bagian komponen tersebut bekerja dan berinteraksi untuk meraih tujuan mereka (Whitten, 2004 : 176).

\subsubsection{Analisa Kinerja Jaringan}

$$
\begin{array}{ll}
\text { Analisa } & \text { kinerja } \\
& \text { jaringan }
\end{array}
$$

didefinisikan sebagai suatu proses untuk menentukan hubungan antara 3 konsep utama, yaitu sumber daya (resources), penundaan (delay) dan daya kerja (throughput). Analisa kinerja mencakup analisa sumber daya dan analisa daya kerja. Dimana kinerja jaringan harus berada pada kondisi yang baik sehingga dapat memberikan pelayanan yang memuaskan, 
maka perlu dilakukan suatu analisis terhadap kinerja jaringan. Analisis kinerja jaringan meliputi perhitungan tingkat penerimaan sinyal, Free space loss, dan System Operating Margin (SOM) jaringan tersebut. Analisis kinerja pada jaringan komputer membicarakan sifat dasar dan karakteristik aliran data, yaitu efisiensi daya kerja, penundaan dan parameter lainnya yang diukur untuk dapat mengetahui bagaimana suatu pesan diproses di jaringan dan dikirim lengkap sesuai fungsinya (Youdant, 2011).

\subsubsection{Jaringan Komputer}

Jaringan komputer adalah dua atau lebih komputer yang terhubung satu sama lain dan digunakan untuk berbagi data. Jaringan komputer dibangun dengan kombinasi hardware dan software.. Dalam bahasa populernya dapat dijelaskan bahwa jaringan komputer merupakan kumpulan beberapa komputer yang saling terhubung dengan lain melalui media perantara seperti media kabel ataupun media tanpa kabel (nirkabel). Berdasarkan skala atau area, jaringan komputer dapat dibagi menjadi 4 bagian,yaitu:

1. LAN (Local Area Network)

Local Area Network adalah jaringan local yang dibuat pada area tertutup.Misalkan dalam satu gedung atau dalam satu ruangan.Kadangkala jaringan local disebut juga jaringan personal atau
private.LAN biasa digunakan pada sebuah jaringan kecil 
yang menggunakan resourse secara bersama, seperti penggunaan printersecara bersama, penggunaan media penyimpanan secara bersama, penggunaan media penyimpanan secara bersama, dan sebagainya.

2. MAN (Metropolitan Area Network) Metropolitan Area Network adalah menggunakan metode yang sama dengan LAN namun daerah cakupanya lebih luas. Daerah cakupan MAN bisa satu RW, beberapa kantor yang berada dalam komplek yang sama, satu/beberapa desa, satu/beberapa kota. Dapat dikatakan MAN merupakan pengembangan dari LAN.

3. WAN (Wide Area Network) Wide Area Network adalah cakupannya lebih luas dari pada MAN. Cakupan WAN meliputi satu kawasan, satu negara, satu pulau, bahkan, satu dunia. Metode yang digunakan WAN hampir sama dengan LAN dan MAN. Umumnya WAN dihubungkan dengan jaringan telepon digital. Namun media transmisi lain pun dapat digunakan.

4. Internet

Internet adalah interkoneksi jaringanjaringan komputer yang ada di dunia.Sehingga cakupanya sudah mencapai satu dunia, bahkan tidak menutup kemungkinan mencakup antarplanet.Koneksi antar jaringan komputer dapat dilakukan berkat

$$
\begin{gathered}
\text { adanya dukungan protokol } \\
\text { yang khasyaitu Internet }
\end{gathered}
$$

Protocol (IP).

\subsubsection{Perangkat Jaringan}

Perangkat keras (Hardware) adalah fisik komputer yang dibedakan dengan data yang berada didalamnya atau beroperasi di dalamnya yang dibedakan dengan perangkat lunak (software) dan menyediakan informasi untuk perangkat keras dalam menyelesaikan tugasnya.Secara umum, perangkat keras/hadwareyang di butuhkan untuk membangun sebuah jaringan komputer yaitu: Network Interface Card (NIC), Swicth, dan semua yang berhubungan dengan koneksi jaringan seperti : Bridges, Router dan lainnya untuk proses transformasi data di dalam jaringan.

\subsubsection{Router}

Router adalah jaringan yang dapat menghubungkan satu jaringan kejaringan lain. Sepintas router mirip dengan bridge, namun router lebih pintar dibandingkan bridge. Router bekerja menggunakan routingtable yang disimpan di memori untuk membuat keputusan tentang kemana paket akan kirimkan. Router dapat memutuskan rule terbaik yang akan ditempuh paket data. 


\section{METODELOGI PENELITIAN}

\subsection{Melakukan \\ Diagnosa \\ (Diagnosing)}

Pada tahapan ini peneliti melakukan identifikasi masalah pokok yang ada dengan cara mengetahui topologi jaringan yang dimiliki oleh SMK Teknologi Bistek Palembang. Sehingga dapat mengetahui seberapa banyak titik pengukuran QoS. Dimana pada tahap ini peneliti akan menampilkan topologi jaringan LAN (Local Area Network) yang peneliti dapat dari SMK Teknologi Bistek Palembang. Berikut gambaran topologi jaringan yang diterapkan di SMK Teknologi Bistek

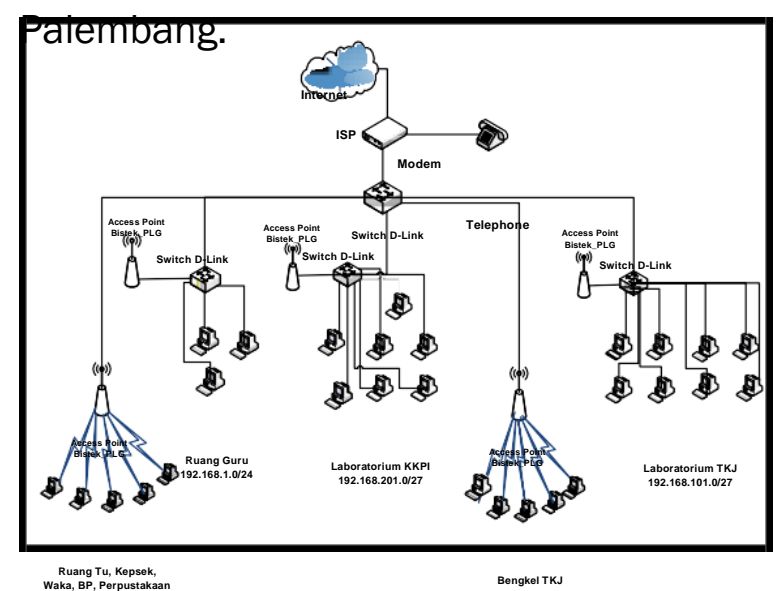

Gambar 3.1. Topologi Jaringan LAN SMK Teknologi Bistek Palembang

\subsection{Membuat Rencana Tindakan (Action PLanning)}

Pada tahap ini peneliti membuat rencana tindakan dengan memahami pokok permasalah yang ada. Dimana setelah melakukan identifikasi terhadap topologi yang ada dan telah ditentukan letak titik pengukurannya kemudian dilanjutkan dengan melakukan persiapan konfigurasi hardware seperti kabel UTP (straight) untuk koneksi laptop dengan masing masing ruangan yang akan dilakukan pengukuran dan menginstal Biznet Speed Meter dan Axence NetTools Versi 5 dan persiapan pengujian terhadap koneksi kinerja jaringan komputer. Dalam penelitian ini akan dilakukan pengukuran parameter QoS (Quality of service) yang terdiri dari bandwidtch, delay, throughput, dan packet loss terhadap kinerja koneksi jaringan komputer terdiri dari empat (4) titik pengukuran yaitu ruang guru, ruang TU, laboratorium KKPI dan laboratorium TKJ.

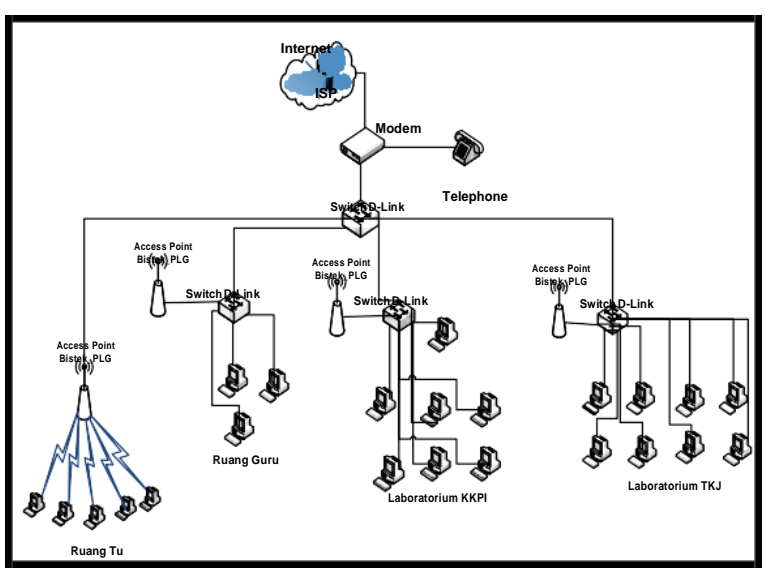

Gambar 3.2. Topologi Area Pengukuran QoS

\subsubsection{Instalasi Biznet Speed Meter}

3.2.2. Instalasi Software Axence

\section{NetTools Versi 5}

Axence NetTools adalah sebuah program siap pakai dimana sebagian besar source code atau listing programnya memiliki perintah dan fungsi untuk menelisik kesalahan atau kelemahan pada 
mesin atau sistem komputeryang dipakai orang lain

\subsubsection{Pengukuran QoS Di Ruang Guru}

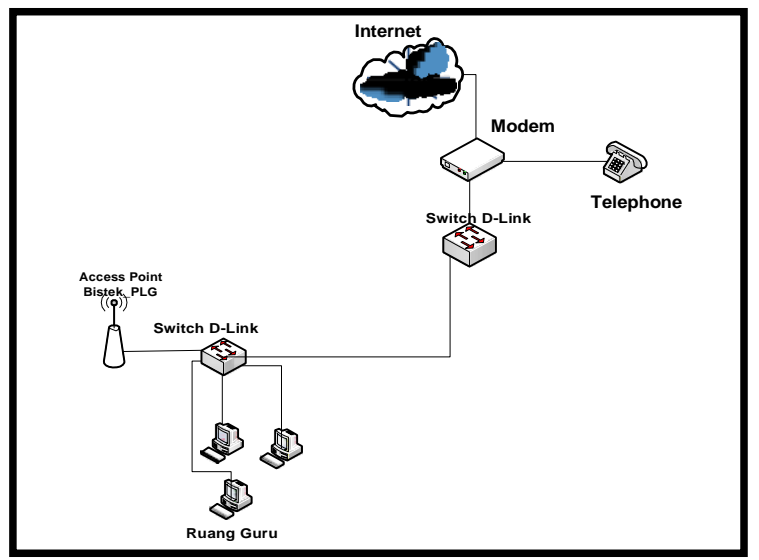

Gambar 3.3. Topologi Pengukuran QoS Di Ruang Guru

Dari gambar topologi diatas menjelaskan bahwa ruang guru yang dilengkapi jaringan internet. Adapun hardware yang digunakan terdiri dari modem, telephone, switch, dan access point. Jaringan komputer ruang guru terdiri dari jaringan LAN dengan bandwidth 1 mbps yang terhubungke switch dan dibagi untuk access point dan komputer LAN. Jumlah pc ada 4 pc yang menggunakan jaringan LAN dengan jumlah pengguna yang tidak tertentu setiap harinya. Proses pengukuran parameter QoS yang terdiri dari bandwidth menggunakan Biznet speed meter ke speedtest.biznetnetworks.com

sedangka

n Delay, Throughput, dan Packet loss yaitu mengunakan Axence NetTools Versi 5 ke website youtobe.co.id

\subsubsection{Pengukuran QoS Di Ruang}

$\mathrm{TU}$

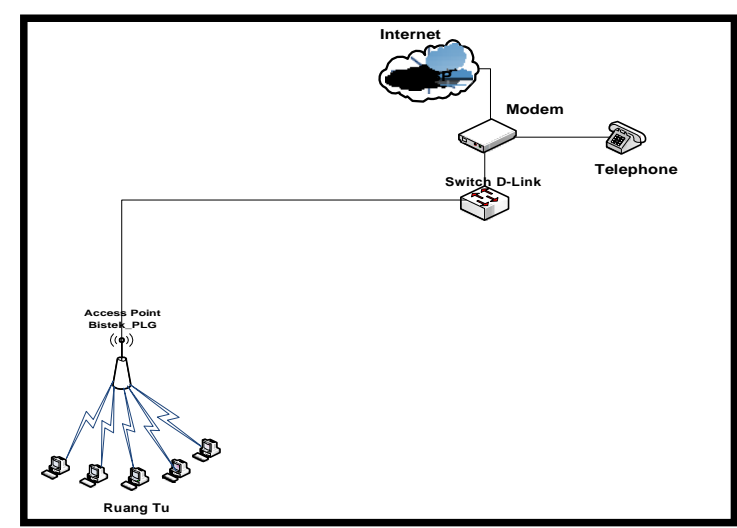

Gambar 3.4. Topologi Pengukuran QoS Di Ruang TU

Dari gambar topologi diatas menjelaskan bahwa ruang TU yang dilengkapi jaringan internet. Adapun hardware yang digunakan terdiri dari modem, telephone, switch, dan access point. Jaringan komputer ruang guru terdiri dari jaringan LAN dengan bandwidth 1 mbps yang terhubung ke switch dan dibagi untuk access point dan komputer LAN. Jumlah pc ada 5 pc yang menggunakan jaringan LAN dengan jumlah pengguna yang tidak tertentu setiap harinya. Proses pengukuran parameter QoS yang terdiri dari bandwidth menggunakan Biznet speed meter ke speedtest.biznetnetworks.com sedangka n Delay, Throughput, dan Packet loss yaitu mengunakan Axence NetTools Versi 5 ke website youtobe.co.id. 


\subsubsection{Pengukuran QoS Di}

\section{Laboratorium KKPI}

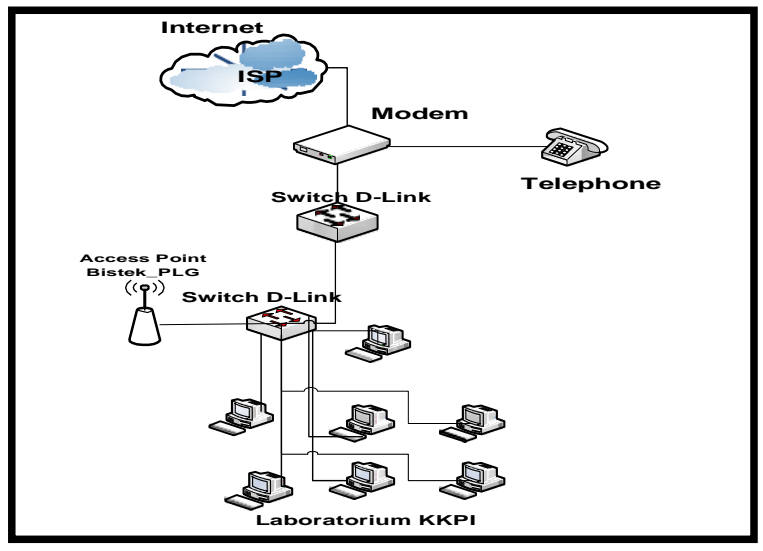

Gambar 3.5. Topologi Pengukuran QoS Di Laboratorium KKPI

Dari gambar topologi diatas menjelaskan bahwa laboratorium KKPI yang dilengkapi jaringan internet. Adapun hardware yang digunakan terdiri dari modem, telephone, switch, dan access point. Jaringan komputer ruang guru terdiri dari jaringan LAN dengan bandwidth 2 mbps yang terhubung ke switch.

\subsubsection{Melakukan Tindakan (Action}

\section{Taking)}

Peneliti melakukan tindakan pengujian dan menganalisa data untuk melihat kinerja koneksi jaringan komputer yang diterapkan pada SMK Teknologi Bistek Palembang dengan memonitoring parameter QoS (Quality of Service) yang terdiri dari parameter bandwidth dengan menggunakan Biznet Speed Meter ke website speedtest.biznetnetworks.com dan delay, throughput, dan packet loss menggunakan Software Axence Net Tools versi 5 dengan mengambil sample website youtobe.co.id pada 
ruang Guru, ruang TU, laboratorium KKPI dan laboratorium TKJ di SMK Teknologi Bistek Palembang.

\subsubsection{Melakukan Evaluasi}

\section{(Evaluating)}

Peneliti melakukan

evaluasi danpenarikkan kesimpulan hasil dari analisis yang telah dilakukan dan data yang telah dikumpulkan akan dibandingkan dengan standar parameter QoS dalam penelitian ini, peneliti menggunakan standarisasi THIPON. Setelah dilakukan perbandingan dari hasil pengukuran QoS dengan menggunakan standarisasi THIPON, maka akan didapat apakah data yang didapat atau pengukuran QoS yang didapat masuk dalam kategori bagus, sedang atau jelek kinerja koneksi jaringan komputer pada SMK Teknologi Bistek Palembang

\section{HASIL DAN PEMBAHASAN}

\subsection{Hasil Pengukuran QoS}

Untuk

mengimplementasikan

rencana yang sudah disusun dan melakukan tindakan pengukuran parameter-parameter dari QoS (Quality of Service), jaringan komputer dengan menggunakan

speedtest.biznetnetworks.com

untuk mengukur

Bandwidth dan Axence NetTools Versi 5 untuk mengukur Delay, Throughput, dan Packet Loss.

\subsubsection{Hasil Pengukuran QoS Ruang} Guru 


\section{Bandwidth}

Dalam proses pengukuran parameter QoS yang terdiri dari bandwidth, delay, throughput, dan packet loss pada perangkat jaringan LAN pada Ruang Guru. Dimana proses pengukurannya dimulai dari hari senin 12 Desember 2016 sampai dengan hari selasa 20 Desember 2016, yang dilakukan pada saat jam sibuk yaitu pukul 08:00 - 11:30 WIB sampai dengan pukul 12:00 - 14:00 WIB dengan menggunakan speedtest. biznetnetworks.com untuk parameter bandwidth. Adapun hasil yang didapat dari pengukuran bandwidth LAN pada ruang guru sebagai berikut :

\begin{tabular}{|c|c|c|c|c|c|c|}
\hline \multicolumn{7}{|c|}{ Tabel 4.1. Nilai Delay Ruang Guru } \\
\hline \multirow[t]{2}{*}{ No } & \multicolumn{2}{|c|}{ Waktu } & \multirow[t]{2}{*}{ Website } & \multicolumn{3}{|c|}{ Delay (ms) } \\
\hline & $\begin{array}{c}\text { Hari/ } \\
\text { Tanggal }\end{array}$ & Pukul & & Min & Maks & $\begin{array}{c}\text { Rata - } \\
\text { Rata }\end{array}$ \\
\hline \multirow[t]{2}{*}{1.} & $\begin{array}{c}\text { Senin } \\
12\end{array}$ & $\begin{array}{l}08: 00- \\
11: 30\end{array}$ & WWW. Youtobe.co.id & 13 & 582 & 49 \\
\hline & $\begin{array}{c}\text { Desember } \\
2016\end{array}$ & $\begin{array}{l}\text { 12:00- } \\
14: 00\end{array}$ & WWW. Youtobe.co.id & 13 & 376 & 35 \\
\hline \multirow[t]{2}{*}{2.} & $\begin{array}{c}\text { Selasa } \\
13\end{array}$ & $\begin{array}{l}\text { 08:00- } \\
11: 30\end{array}$ & WWW. Youtobe.co.id & 13 & 537 & 23 \\
\hline & $\begin{array}{c}\text { Desember } \\
2016\end{array}$ & $\begin{array}{l}\text { 12:00- } \\
14: 00\end{array}$ & WWW. Youtobe.co.id & 13 & 633 & 36 \\
\hline \multirow[t]{2}{*}{3.} & $\begin{array}{c}\text { Rabu } \\
14\end{array}$ & $\begin{array}{l}08: 00- \\
11: 30\end{array}$ & WWW. Youtobe.co.id & 13 & 348 & 30 \\
\hline & $\begin{array}{c}\text { Desember } \\
2016\end{array}$ & $\begin{array}{l}12: 00- \\
14: 00\end{array}$ & WWW. Youtobe.co.id & 13 & 698 & 36 \\
\hline \multirow[t]{2}{*}{4.} & $\begin{array}{c}\text { Kamis } \\
15\end{array}$ & $\begin{array}{l}\text { 08:00- } \\
11: 30\end{array}$ & WWW. Youtobe.co.id & 13 & 685 & 65 \\
\hline & $\begin{array}{c}\text { Desember } \\
2016\end{array}$ & $\begin{array}{l}\text { 12:00 } \\
14: 00\end{array}$ & WWW. Youtobe.co.id & 13 & 376 & 35 \\
\hline \multirow[t]{2}{*}{5.} & $\begin{array}{c}\text { Senin } \\
19\end{array}$ & $\begin{array}{l}\text { 08:00- } \\
11: 30\end{array}$ & WWW. Youtobe.co.id & 13 & 678 & 47 \\
\hline & $\begin{array}{c}\text { Desember } \\
2016\end{array}$ & $\begin{array}{l}\text { 12:00- } \\
14: 00\end{array}$ & WWW. Youtobe.co.id & 13 & 633 & 36 \\
\hline \multirow[t]{2}{*}{6.} & $\begin{array}{c}\text { Selasa } \\
20\end{array}$ & $\begin{array}{l}\text { 08:00- } \\
11: 30\end{array}$ & WWW. Youtobe.co.id & 13 & 741 & 45 \\
\hline & $\begin{array}{c}\text { Desember } \\
2016\end{array}$ & $\begin{array}{l}\text { 12:00- } \\
14: 00\end{array}$ & WWW. Youtobe.co.id & 13 & 424 & 30 \\
\hline
\end{tabular}

Tabel 4.1 hasil pengukuran delay

\subsubsection{Hasil Pengukuran QoS Ruang} TU

\section{Bandwidth}

Dalam proses pengukuran parameter QoS yang terdiri dari bandwidth, delay, throughput, dan packet loss pada perangkat jaringan LAN pada Laboratorium KKPI. Dimana proses pengukurannya dimulai dari hari senin 12 Desember 2016 sampai dengan hari selasa 20 Desember 2016 , yang dilakukan pada saat jam sibuk yaitu pukul 08:00 - 11:30 WIB sampai dengan pukul 12:00 - 14:00 WIB dengan menggunakan

speedtest.biznetnetworks.com

untu

$\mathrm{k}$ parameter bandwidth. Adapun hasil yang didapat dari pengukuran bandwidth LAN pada ruang guru sebagai berikut:

\begin{tabular}{|c|c|c|c|c|c|c|}
\hline \multicolumn{7}{|c|}{ Tabel 4.2) Nilai Delay Ruang TU } \\
\hline \multirow[t]{2}{*}{ No } & \multicolumn{2}{|c|}{ Waktu } & \multirow[t]{2}{*}{ Website } & \multicolumn{3}{|c|}{ Delay (ms) } \\
\hline & $\begin{array}{c}\text { Hari/ } \\
\text { Tanggal }\end{array}$ & Pukul & & Min & Maks & Rata - Rata \\
\hline \multirow[t]{2}{*}{1.} & $\begin{array}{c}\text { Senin } \\
12\end{array}$ & $\begin{array}{l}08: 00- \\
11: 30\end{array}$ & WWW. Youtobe.co.id & 13 & 547 & 32 \\
\hline & $\begin{array}{c}\text { Desember } \\
2016\end{array}$ & $\begin{array}{l}12: 00- \\
14: 00\end{array}$ & WWW. Youtobe.co.id & 13 & 698 & 36 \\
\hline \multirow[t]{2}{*}{2.} & $\begin{array}{c}\text { Selasa } \\
13\end{array}$ & $\begin{array}{l}08: 00- \\
11: 30\end{array}$ & WWW. Youtobe.co.id & 13 & 936 & 147 \\
\hline & $\begin{array}{c}\text { Desember } \\
2016\end{array}$ & $\begin{array}{l}12: 00- \\
14: 00\end{array}$ & WWW. Youtobe.co.id & 13 & 376 & 35 \\
\hline \multirow[t]{2}{*}{3.} & $\begin{array}{c}\text { Rabu } \\
14\end{array}$ & $\begin{array}{l}08: 00- \\
11: 30\end{array}$ & WWW. Youtobe.co.id & 13 & 427 & 51 \\
\hline & $\begin{array}{c}\text { Desember } \\
2016 \\
\end{array}$ & $\begin{array}{l}12: 00- \\
14: 00\end{array}$ & WWW. Youtobe.co.id & 13 & 893 & 44 \\
\hline 4. & $\begin{array}{c}\text { Kamis } \\
15\end{array}$ & $\begin{array}{l}08: 00- \\
11: 30\end{array}$ & WWW. Youtobe.co.id & 13 & 483 & 48 \\
\hline
\end{tabular}

Tabel 4.2 hasil pengukuran delay

\subsubsection{Hasil Pengukuran QoS}

\section{Laboratorium KKPI}

\section{Bandwidth}

Dalam proses pengukuran parameter QoS yang terdiri dari bandwidth, delay, throughput, dan packet loss pada perangkat jaringan LAN pada Laboratorium KKPI. Dimana proses pengukurannya dimulai dari hari senin 12 Desember 2016 sampai dengan hari selasa 20 Desember 2016, yang 
dilakukan pada saat jam sibuk yaitu pukul 
08:00 - 11:30 WIB sampai dengan pukul 12:00 - 14:00 WIB dengan menggunakan speedtest.biznetnetworks.com

untu

$\mathrm{k}$ parameter bandwidth. Adapun hasil yang didapat dari pengukuran bandwidth LAN pada ruang guru sebagai berikut :

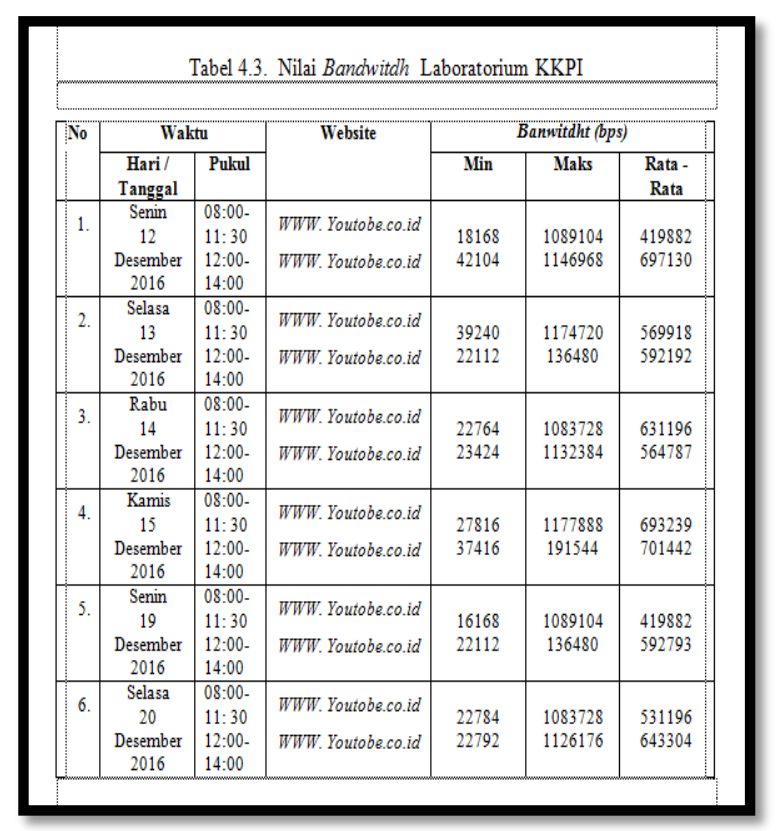

Tabel 4.3 Hasil pengukuran Bandwitdh

\subsubsection{Hasil Pengukuran QoS}

\section{Laboratorium TKJ}

\section{Bandwidth}

Dalam proses pengukuran parameter QoS yang terdiri dari bandwidth, delay, throughput, dan packet loss pada perangkat jaringan LAN pada Laboratorium KKPI. Dimana proses pengukurannya dimulai dari hari senin 12 Desember 2016 sampai dengan hari selasa 20 Desember 2016, yang dilakukan pada saat jam sibuk yaitu pukul 08:00 - 11:30 WIB sampai dengan pukul 12:00 - 14:00 WIB dengan menggunakan speedtest.biznetnetworks.com untuk parameter bandwidth. Adapun hasil yang didapat dari pengukuran bandwidth LAN pada ruang guru sebagai berikut :

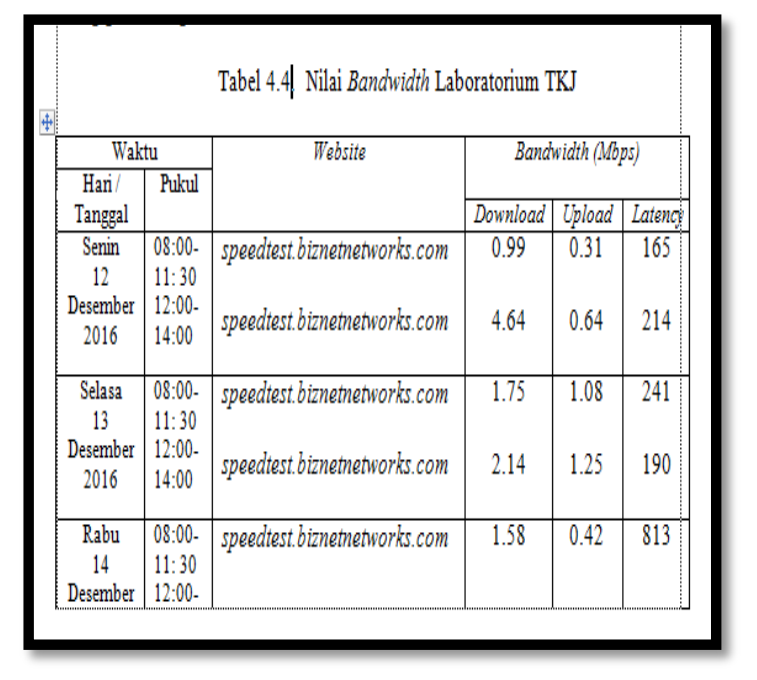

Tabel 4.4. Hasil Pengukuran Bandwidth

\section{PENUTUP}

\subsection{Kesimpulan}

Dari hasil pengukuran, pemantauan dan analisa kinerja koneksi jaringan komputer pada SMK Teknologi Bistek Palembang, didapatkan kesimpulan sebagai berikut ini :

1. Quality of Service (QOS) jaringan komputer yang terdiri dari bandwidth, delay, troughput dan packet loss, , dan untuk pengukuran dari client terhadap server berpengaruh terhadap QOS jaringan LAN pada SMK Teknologi Bistek Palembang terutama pada Laboratorium KKPI dan Laboratorium TKJuntuk tiap-tiap perangkat hardware dan software.

2. Faktor-faktor yang dapat mempengaruhi QOS jaringan komputer pada SMK Teknologi Bistek Palembang adalah redaman, distorsi, dan noise. Kapasitas 
bandwidth yang tersedia juga http;//www.slideslinder.com). mempengaruhi kinerja QOS jaringan komputer.

3. Faktor yang mempengaruhi hasil pengukuran ini adalah pertambahan jarak pada media transimisi jaringan komputer baik media kabel maupun media WiFi sehingga menyebabkan packet loss propagasi yang besar selain itu waktu proses yang melewati beberapa alat dan media mempengaruhi waktu packet loss untuk setiap perangkat yang diukur.

Setelah dilakukannya pengukuran terhadap jarigan komputer dapat disimpulkan bahwa dari rendahnya pengukuran bandwidth dan troughput serta tingginya nilai packet loss hal ini disebabkan oleh karena banyaknya pengguna

\section{DAFTAR PUSTAKA}

Artikel non-personal, 2013, Axence Nettols pro 5.0, diakses Oktober 2016, dari (http;//www.Axencesoftware.com).

Chandra, 2088. Action Research. (http;//chandrax.wordpress.com/20 08/ 07/2005/action reselarch penelitian- tindakan/ : diakses 10 april 2013).

Eko Dewangga, 2015, Flowchrt CSMA/CD, diakses 8 november 2016, dari 
Fatoni, 2011. Analisis Kualitas Layanan Internet (Studi kasus: Universitas bina darma palembang). Diakses pada tanggal 20 oktober 201

6. http://blog.binadarma.ac.id/fatoni/log in/w $\mathrm{p}-$ content/uploads/2012/11/proshedin g.

Iwan, Sofana. (2014). Cisco CCNA dan Jaringa Komputer . Penerbit Informatika. Bandung. ISBN 978-6028758-77-2.

M. Dwi Saputra , A. Yani Ranius, Dian Purnama Sari (2015). Jurnal Analisis jaringan local area network Pada AMIK Lembah Dempo Pagar Alam Menggunakan Metode QOS dan RMA. Mahasiswi Universitas Bina Darma Paalembang dan Dosen Universitas Bina Darma.

Nurdina Trilisman Putri, Alex Wijaya, Usman Ependi (2012). Jurnal Anlisis Quality Of Service (QOS) Jaringan Internet Pada SMK Negeri 4 Palembang Mahasiswi Universitas Bina Darma Palembang.

Ramadhon, Pratama, Pearl. „Analisis Kinerja jaringan wireless lan menggunakan metode QOS dan RMA Pada PT Pertamina Ep Ubep Ramba (persero). http://eprints.binadarma.ac.id/115/., 2013.

Diakses 20 oktober 2016. http://youdant.wordpress.com/2011/0 6/13/ 98/ : diakses pada 20 Oktober 2016). 